\title{
Safety of users in road evacuation: RP vs. SP surveys in demand analysis
}

\author{
F. Russo \& G. Chilà \\ LAST - Laboratory for Transport Systems Analysis \\ DIMET - Department of Computer Science, Mathematics, \\ Electronics and Transportation, \\ Mediterranea University of Reggio Calabria, Italy
}

\begin{abstract}
An advancement on demand models for the simulation of a transportation system in emergency conditions is the aim of this work. Advancement is related to demand models specified for the research project SICURO, organized by the Laboratory for Transport Systems Analysis (LAST). Herein we propose specification and calibration of generation and distribution with modal choice models. In comparison with demand models previously presented, a generation model according to a behavioural approach is proposed. Major attention is focused on SP (Stated Preference) surveys, in comparison with the RP (Revealed Preference) surveys previously considered.
\end{abstract}

Keywords: emergency condition, simulation, demand model.

\section{Introduction}

Demand models are a fundamental tool for most problems in the planning and management of transport systems. Travel demand is usually expressed by origindestination matrices, whose elements represent the number of users, belonging to a socio-economic segment, travelling from each origin to each destination in a defined time period by each mode of transport [3]. Several mathematical models to simulate travel demand are proposed in the literature. These are based on different assumptions and can be subdivided in relation to different elements $[1,4,5]$. Generally, these models are applied to simulate transport demand in ordinary conditions. 
When a dangerous event occurs (emergency conditions) demand models specified and calibrated in ordinary conditions cannot be directly applied for several reasons: multiplicity of decision-makers (mayor and citizen); choice set (which may differ for emergency scenarios and for decision makers); statistical and probabilistic aspects; attributes and parameters.

Moreover, in emergency conditions the analyst must consider possible targets set by the public decision-maker, in order to reduce system management costs, maximise the system utility (safety, security) and reduce traffic accidents [8]. Targets can be established in relation to different choice dimensions: generation (whether or not the mayor fixes the order of evacuation in a specific target time); distribution (if the mayor assigns refuge areas for each user category); modal choice (if the mayor decides the transport mode for each user category); route choice (if the mayor fixes paths for each user category).

Different demand models have to be specified, in relation to event types, which can be classified according to their effects in space and in time $[7,10,12,13]$. In relation to these effects, several emergency scenarios can be defined.

In the international literature, one kind of natural event analyzed is the hurricane. When dealing with hurricane evacuation, travel demand estimation is usually subdivided into two steps: estimation of total evacuation demand and estimation of departure time [15]. Generally, these steps are developed considering a statistical approach, using simple relationships such as means, rates and distributions. For example, the most common method of estimating evacuation demand is to use evacuation participation rates of evacuation zones, according to the severity of the storm and past observed behaviour [14]. Some researchers use a response curve, sensitive to the characteristics of the hurricane, to simulate evacuation demand. Such curves are subjectively established, based on past evacuation behaviour, and relate the proportion evacuating to the time elapsing from an evacuation order being issued [16]. In some specifications, the decision to evacuate is simulated as a series of binary choices over time [14]. In the literature on hurricanes, there exist large data collections which allow demand model estimation by means of RP (revealed preference) surveys. RP surveys include preferences inferred from observations of a decision maker's actual choices, in relation to real contexts. However, since RP data are not available for all dangerous events, models specified for hurricane evacuation, which are derived from observation of past evacuation behaviour, cannot be directly applied to other dangerous events. Demand model estimation becomes a complex problem, particularly when unpredictable events happen and users fail to respect targets set by the public decision maker. Prediction of user behaviour becomes essential. For this purpose, evacuation trials and SP (stated preference) surveys may be conducted. Such surveys represent the stated behaviour of users in relation to hypothetical contexts. During evacuation trials, RP data can be obtained, even if they are affected by the laboratory effect, because each user participating in evacuation trials knows that he/she runs no real danger. Therefore, RP surveys during evacuation trials are a statement of behaviour in emergency conditions, similar to SP surveys with physical verification. SP 
surveys allow us to simulate several emergency scenarios, which can differ in user category, in the effect in space and time of the dangerous event.

SP surveys must be designed, defining: emergency scenarios, based on the set of alternative options; attributes for each alternative; variation in level of attributes; choice mechanism [2,4]. Proposed emergency scenarios must be characterized by the description of: period of reference, targets, effects produced in time and space. Proposed scenarios must be realistic and clear, in order to limit distortions between real and stated behaviour. Possible distortions can be removed by comparing SP data with observed flows [9] during evacuation trials, from which an origin/destination matrix can be estimated. In light of such considerations, SP surveys play a very important role and RP surveys during evacuation trials may be viewed as physical checking SP data.

In this paper we propose advancements in the specification and calibration of a model simulating transport demand in emergency conditions. We assume a disaster event with a delayed effect in the time and a diffuse effect in the space, in relation to simulations carried out in the SICURO research project [10]. Unlike demand models previously presented [12,13], a generation model according to a behavioural approach is proposed. Great attention is devoted to SP surveys in comparison with previously considered RP surveys. In section 2 we describe the proposed demand model; in section 3 we describe the experiment and calibrated parameters; in the last section we present the main conclusions and future objectives.

\section{Proposed demand model}

The proposed demand model includes a generation model, specified and calibrated according to two different approaches; a modal choice model; a distribution model; a first example of modal choice with distribution model.

In order to facilitate comparison with ordinary conditions, a multi-step demand model is proposed. The consolidated model series, considered in ordinary conditions, is modified in relation to order and structure of simulated choices. For example, for some user categories, we assume the absence of a target (imposed by the mayor), in relation to destination and modal choice. In other words, the citizen user can decide to where and by what means to evacuate. In this case, we note that either the decision-maker chooses the refuge area and the transport mode at the same time or he/she chooses the transport mode first and then the destination.

\subsection{Specification of descriptive and behavioural generation model}

Given an emergency scenario, the generation model simulates the mean number of people of category $\mathrm{k}$ to evacuate in the study area in the reference period.

In this work we consider:

- $\quad$ the citizen user as the decision maker;

- a choice set including the alternatives present or otherwise in the reference period and, for people present, the alternatives willing or not to evacuate; 
- $\quad$ attributes and parameters related to socio-economic property;

- $\quad$ descriptive (A) and behavioural (B) approach.

Moreover, we consider the absence of targets.

The model was developed for the following categories:

- $\quad$ residents within the area $(\mathrm{R})$;

- $\quad$ non-residents who systematically reach the area for work (employees, W), and, in particular, teachers and pupils (school, S);

- non-residents who occasionally reach the area for shopping or other activities (occasional customers, C);

- weak users (D).

Demand $d_{E, r}(h)$ of those present in the study area in the reference period $h$, per category, will be:

$$
d_{E, r}(h)=d_{E, r}^{R}(h)+d_{E, r}^{W}(h)+d_{E, r}^{C}(h)+d_{E, r}^{S}(h)+d_{E, r}^{D}(h)
$$

with

$\mathrm{d}_{\mathrm{E}, \mathrm{r}}^{\mathrm{R}}(\mathrm{h}) \quad$ demand of those present in the resident category;

$\mathrm{d}_{\mathrm{E}, \mathrm{r}}^{\mathrm{W}}(\mathrm{h}) \quad$ demand of those present in the employee category;

$\mathrm{d}_{\mathrm{E}, \mathrm{r}}^{\mathrm{C}}(\mathrm{h}) \quad$ demand of those present in the occasional customer category;

$\mathrm{d}_{\mathrm{E}, \mathrm{r}}^{\mathrm{S}}(\mathrm{h}) \quad$ demand of those present in the school (including pupils, teachers and employees);

$\mathrm{d}_{\mathrm{E}, \mathrm{r}}^{\mathrm{D}}(\mathrm{h}) \quad$ demand of those present in the weak user category,

The demand of those in the resident category can be specified as:

$$
d_{E, r}^{R}(h)=n_{r}^{R}(h) \cdot m_{E}^{R}(h)
$$

with

$\mathrm{n}_{\mathrm{r}}^{\mathrm{R}}(\mathrm{h}) \quad$ resident number in zone $\mathrm{r}$;

$\mathrm{m}_{\mathrm{E}}^{\mathrm{R}}(\mathrm{h}) \quad$ generation coefficient computed according to two ways:

1. $\mathrm{m}_{\mathrm{E}}^{\mathrm{R}}(\mathrm{h})=\alpha_{\mathrm{FL}}(\mathrm{h}) \cdot \mathrm{PFL}_{\mathrm{r}}+\alpha_{\mathrm{SR}}(\mathrm{h}) \cdot \mathrm{PSR}_{\mathrm{r}}+\alpha_{\mathrm{P}}(\mathrm{h}) \cdot \mathrm{PP}_{\mathrm{r}}+\alpha_{\mathrm{C}}(\mathrm{h}) \cdot \mathrm{PC}_{\mathrm{r}}$

with

$\mathrm{PFL}_{\mathrm{r}}$ worker percentage in zone $\mathrm{r}$;

$\mathrm{PSR}_{\mathrm{r}}$ student percentage in zone $\mathrm{r}$;

$\mathrm{PP}_{\mathrm{r}} \quad$ retired percentage in zone $\mathrm{r}$;

$\mathrm{PC}_{\mathrm{r}}$ housewife percentage in zone $\mathrm{r}$;

$\alpha_{\mathrm{FL}}(\mathrm{h}), \alpha_{\mathrm{SR}}(\mathrm{h}), \alpha_{\mathrm{P}}(\mathrm{h}), \alpha_{\mathrm{C}}(\mathrm{h})$ calibrating parameters.

or

$$
\text { 2. } \begin{aligned}
\mathrm{m}_{\mathrm{E}}^{\mathrm{R}}(\mathrm{h})= & \alpha_{\mathrm{R}_{2}}(\mathrm{~h}) \cdot \mathrm{PR}_{2, \mathrm{r}}+\alpha_{\mathrm{R}_{3}}(\mathrm{~h}) \cdot \mathrm{PR}_{3, \mathrm{r}}+\alpha_{\mathrm{R}_{4}}(\mathrm{~h}) \cdot \mathrm{PR}_{4, \mathrm{r}}+\alpha_{\mathrm{R}_{5}}(\mathrm{~h}) \cdot \\
& \mathrm{PR}_{5, \mathrm{r}}+\alpha_{\mathrm{R}_{6}}(\mathrm{~h}) \cdot \mathrm{PR}_{6, \mathrm{r}}
\end{aligned}
$$

with

$\mathrm{PR}_{2, \mathrm{r}}$ resident percentage of age in $[5,14]$;

$\mathrm{PR}_{3, \mathrm{r}}$ resident percentage of age in $[15,19]$;

$\mathrm{PR}_{4, \mathrm{r}}$ resident percentage of age in $[20,24]$; 
$\mathrm{PR}_{5, \mathrm{r}}$ resident percentage of age in $[25,65]$;

$\mathrm{PR}_{6, \mathrm{r}}$ resident percentage older than 65 years;

$\alpha_{R_{2}}(h), \alpha_{R_{3}}(h) \cdot, \alpha_{R_{4}}(h), \alpha_{R_{5}}(h), \alpha_{R_{6}}(h)$ calibrating parameters.

The demand of those in the other categories can be specified as:

$$
\mathrm{d}_{\mathrm{E}, \mathrm{r}}^{\mathrm{k}}(\mathrm{h})=\mathrm{n}_{\mathrm{r}}^{\mathrm{k}}(\mathrm{h}) \cdot \mathrm{m}_{\mathrm{E}}^{\mathrm{k}}(\mathrm{h})
$$

where

$\mathrm{n}_{\mathrm{r}}^{\mathrm{k}}(\mathrm{h})$ is the number of user of category $\mathrm{k}$ in zone $\mathrm{r}$, with $\mathrm{k}$ category index equal to:

W for employees and occasional customers;

S for schools;

D for weak users;

$\mathrm{m}_{\mathrm{E}}^{\mathrm{k}}(\mathrm{h})$ calibrating parameter, with $\mathrm{k}$ equal to:

W for employees;

C for occasional customers;

S for schools;

D for weak users.

It is worth pointing out that the demand of those in the occasional customer category is specified as a function of employee number.

Demand of those willing to evacuate can be specified according to:

(A) Descriptive approach

$$
\mathrm{d}_{\mathrm{E}_{\xi}, \mathrm{r}}(\mathrm{h})=\sum_{\mathrm{k}} \mathrm{d}_{\mathrm{E}_{\xi}, \mathrm{r}}^{\mathrm{k}}(\mathrm{h})=\sum_{\mathrm{k}} \mathrm{d}_{\mathrm{E}, \mathrm{r}}^{\mathrm{k}}(\mathrm{h}) \cdot \xi^{\mathrm{k}}
$$

with category index $\mathrm{k}$ and calibrating parameter $\xi^{\mathrm{k}}$;

(B) Behavioural approach

A behavioural binary model to simulate present users' willingness to evacuate is proposed. The model is generic, for all categories.

We assume the absence of targets and:

- $\quad$ the citizen user as the decision-maker;

- a choice set including the alternative to evacuate or not to evacuate;

- attributes and parameters related to socio-economic properties and alternative specific attributes (ASA);

- a behavioural approach, with random residual $\varepsilon_{\mathrm{j}}$ independently and identically distributed according to a Gumbel random variable of zero mean and parameter $\theta$.

In the following we propose an example of specification of systematic utility for the alternatives:

$$
\begin{gathered}
\mathrm{V}_{\text {evacuate }}=\beta_{\mathrm{Women}} \cdot \text { Women }+\beta_{\mathrm{W}_{-} \mathrm{PU}} \cdot \mathrm{W}_{-} \mathrm{PU}+\beta_{\mathrm{DL}} \cdot \mathrm{DL}+\beta_{\mathrm{CO}} \cdot \mathrm{CO}+ \\
\beta_{\text {Centre }} \cdot \text { Centre } \\
\mathrm{V}_{\text {not_evacuate }}=\beta_{\mathrm{R}} \cdot \mathrm{R}+\beta_{\mathrm{NOFL}} \cdot \mathrm{NOFL}
\end{gathered}
$$

with

Women dummy equal to 1 for women, 0 otherwise; $\mathrm{R} \quad$ dummy equal to 1 for residents, 0 otherwise;

NOFL dummy equal to 1 for unemployed, 0 otherwise; 
W_PU dummy equal to 1 for employed in the public sector, 0 otherwise;

Centre dummy equal to 1 if the origin is in central zone, 0 otherwise;

DL dummy equal to 1 for users with a driving licence, 0 otherwise;

$\mathrm{CO}$ dummy equal to 1 for users owning vehicle, 0 otherwise.

\subsection{Specification of modal choice and distribution models}

Given an emergency scenario, the modal choice model simulates the number of people using a transport mode from a certain origin to a certain refuge area; the distribution model simulates the probability of trips undertaken by people going to a certain refuge area, given departure from zone $r$ in period $h$.

In this work we assume a modal choice model and distribution are targeted for school staff and weak user categories.

For the remaining categories we suppose the absence of targets, the citizen user as the decision-maker and a behavioural approach, with random residual $\varepsilon_{\mathrm{j}}$ independently and identically distributed according to a Gumbel random variable of zero mean and parameter $\theta$. We propose:

$\mathrm{a}_{1} \quad$ a modal choice model;

$\mathrm{a}_{2} \quad$ a distribution model;

$\mathrm{b}_{12} \quad$ a modal split with a distribution model.

We propose several specifications: some of them are related to the whole population, others to particular employee groups.

For the modal choice model $\left(\mathrm{a}_{1}\right)$ we assume the absence of targets and:

- a choice set including car and pedestrian alternatives;

- attributes and parameters related to level of service, socio-economic properties and alternative specific attributes (ASA).

The systematic utility for the alternatives will be specified as:

$$
\begin{aligned}
\mathrm{V}_{\text {pedestrian }} & =\beta_{\mathrm{R}_{5}} \cdot \mathrm{R}_{5}+\beta_{\text {Women }} \cdot \text { Women }+\beta_{\mathrm{DP}_{\mathrm{rc}}} \mathrm{DP}_{\mathrm{rc}} \\
\mathrm{V}_{\mathrm{car}} & =\beta_{\mathrm{L}} \cdot \mathrm{L}+\beta_{\mathrm{CWork}} \mathrm{CWork}
\end{aligned}
$$

with

$\mathrm{R}_{5} \quad$ dummy equal to 1 for citizen users of age in range $[25,45]$;

Women dummy equal to 1 for women, 0 otherwise;

$\mathrm{DP}_{\mathrm{rc}}$ distance on the pedestrian network between origin $\mathrm{r}$ and refuge area $\mathrm{c}$;

L economic dummy (professional level);

CWork dummy equal to 1 if the worker used a car to go to work, 0 otherwise.

For the distribution model $\left(\mathrm{a}_{2}\right)$ we assume a refuge area established by the public decision-maker and:

- a choice set which includes the alternatives of refuge area fixed by the public decision maker (cf) or other refuge area (ncf);

- $\quad$ attributes and parameters related to level of service, socio-economic properties and alternative specific attributes (ASA).

The systematic utility for the alternatives will be specified as:

$$
\begin{aligned}
& \mathrm{V}_{\mathrm{cf}}=\beta_{\mathrm{L}} \cdot \mathrm{L}+\beta_{\text {Women }} \cdot \text { Women } \\
& \mathrm{V}_{\mathrm{ncf}}=\beta_{\mathrm{r}_{\mathrm{p}}} \cdot \mathrm{r}_{\mathrm{p}}+\beta_{\mathrm{D}_{\mathrm{r}, \mathrm{ncf}}} \mathrm{D}_{\mathrm{r}, \text { ncf }}
\end{aligned}
$$


with

Women dummy equal to 1 for women, 0 otherwise;

L dummy (professional level);

$r_{p} \quad$ dummy equal to 1 for origin not in the centre of evacuating area, 0 otherwise.

$\mathrm{D}_{\mathrm{r}, \mathrm{ncf}}$ distance as the crow flies between origin $\mathrm{r}$ and refuge area ncf.

The proposed distribution model is not designed to simulate citizen user choice as a usual distribution model. According to a behavioural approach, the usual distribution model simulates destination choice, as a homogeneous area including several elementary destinations, which are represented as discrete points $[1,4]$. In this work, the proposed distribution model is related to the possibility that the citizen user may or may not follow the decision maker's advice. Alternatives are not homogeneous areas, but discrete points fixed by a decision-maker. In this case the level of service attributes are not significant to simulate citizen user behaviour; only socio-economic variables are used [13].

For modal choice with distribution model $\left(b_{12}\right)$ we assume the absence of constraints and:

- $\quad$ a choice set which includes the alternatives: pedestrian with fixed refuge area (cf,pedestrian), pedestrian with non-fixed refuge area (ncf,pedestrian), car with fixed refuge area (cf,car);

- $\quad$ attributes and parameters related to level of service.

The systematic utility for the alternatives will be specified as:

$$
\begin{aligned}
& \mathrm{V}_{\mathrm{cf}, \text { pedestrian }}=\beta_{\mathrm{TP}_{\mathrm{r}, \mathrm{cf}}} \cdot \mathrm{TP}_{\mathrm{r}, \mathrm{cf}} \\
& \mathrm{V}_{\mathrm{ncf}, \text { pedestrian }}=\beta_{\mathrm{TP}_{\mathrm{r}, \mathrm{ncf}}} \cdot \mathrm{TP}_{\mathrm{r}, \mathrm{ncf}} \\
& \mathrm{V}_{\mathrm{cf}, \mathrm{car}}=\beta_{\mathrm{TS}_{\mathrm{r}, \mathrm{cf}}} \cdot \mathrm{TS}_{\mathrm{r}, \mathrm{cf}}
\end{aligned}
$$

with

$\mathrm{TP}_{\mathrm{r}, \mathrm{cf}}$ time on pedestrian network from origin $\mathrm{r}$ to fixed refuge area $\mathrm{c}$;

$\mathrm{TP}_{\mathrm{r}, \mathrm{ncf}}$ time on pedestrian network from origin $\mathrm{r}$ to non-fixed refuge area ncf;

$\mathrm{TS}_{\mathrm{rc}}$ time on road network from origin $\mathrm{r}$ to fixed refuge area $\mathrm{c}$.

\section{Experimentation}

The advanced proposed model was calibrated using the data obtained from a real experiment in the urban area of Melito Porto Salvo (Italy), in relation to the SICURO research project $[12,13]$. We performed pre-trial and trial evacuation. For users of each evacuation zone we conducted:

- $\quad$ a pre-trial RP survey, to ascertain socio-economic properties;

- a pre-trial SP survey, to estimate the number of people usually present and their willingness to evacuate;

- a post-trial RP survey, to ascertain the characteristics of the evacuated users.

The proposed emergency scenario in SP surveys is characterized by: morning period of reference; targets fixed for given user categories; delayed effects in time and area effect in space. Surveys allow the estimation of: present users, by socio-economic category, in the period of reference and in the evacuation area; 
present users willing to evacuate; destination and transport mode chosen to evacuate. Targeted emergency scenarios are used in order to evaluate the willingness of users to follow indications of the public decision maker.

Importantly, data obtained from SP surveys could be distorted. Distortions regard possible differences between stated and real choice behaviour, particularly if the dangerous event produces an immediate effect in time. In these conditions, users can be seized by panic[6]. In this work we assumed a dangerous event with delayed effects in time: such data obtained from SP surveys can be considered reliable. Data were recorded and developed by laboratory analysis in order to calibrate the proposed model. The generation model was calibrated using the least squares method (approach A) and the maximum likelihood method (approach B); modal choice and distribution model were calibrated using the maximum likelihood method. In tables 1-6 calibrated parameters are reported.

Table 1: Generation model by resident category.

\begin{tabular}{|c|c|c|c|c|c|}
\hline \multicolumn{2}{|c|}{ Parameter } & \multirow{2}{*}{$\begin{array}{c}\text { Value } \\
0.13\end{array}$} & \multirow{2}{*}{$\begin{array}{c}\text { t-Statistic } \\
(2.82)\end{array}$} & \multirow[t]{2}{*}{ Value } & \multirow[t]{2}{*}{ t-Statistic } \\
\hline$\alpha_{\mathrm{FL}}$ & Worker percentage & & & & \\
\hline$\alpha_{\mathrm{SR}}$ & Student percentage & 0.33 & $(4.74)$ & & \\
\hline$\alpha_{\mathrm{C}}$ & Housewife percentage & 1.00 & $(42.36)$ & & \\
\hline$\alpha_{p}$ & Retired percentage & 0.14 & $(2.55)$ & & \\
\hline$\alpha_{\mathrm{R}_{2}}$ & Percentage of residents with age between $[5,14]$ & & & -0.09 & $(-0.28)$ \\
\hline$\alpha_{\mathrm{R}_{3}}$ & Percentage of residents with age between $[15,19]$ & & & -0.83 & $(-1.16)$ \\
\hline$\alpha_{\mathrm{R}_{4}}$ & Percentage of residents with age between $[20,24]$ & & & -0.32 & $(-0.46)$ \\
\hline$\alpha_{\mathrm{R}_{5}}$ & Percentage of residents with age between $[25,65]$ & & & 0.80 & $(8.36)$ \\
\hline$\alpha_{\mathrm{R}_{6}}$ & Percentage of residents older than 65 years & & & -0.15 & $(-0.51)$ \\
\hline$\xi^{\mathrm{R}}$ & Willingness to evacuate by resident category & 0.24 & $(0.50)$ & 0.24 & $(0.50)$ \\
\hline
\end{tabular}

Table 2: $\quad$ Behavioural generation model for evacuation willingness.

\begin{tabular}{llcccccc}
\hline Parameter & & UdM & Alt. & Value & t-Statistic & Value & t-Statistic \\
\hline$\beta_{\text {age 25 65 }}$ & age between [25,65] & {$[0,1]$} & 2 & & & -0.344 & $(-1.1)$ \\
$\beta_{\text {NOFL }}$ & unemployed & {$[0,1]$} & 2 & 1.398 & $(1.2)$ & 1.272 & $(1.1)$ \\
$\beta_{\mathrm{R}}$ & resident & {$[0,1]$} & 2 & 0.814 & $(2.8)$ & 0.882 & $(2.5)$ \\
$\beta_{\mathrm{W} \text { PU }}$ & public sector employee & {$[0,1]$} & 1 & 0.644 & $(2.0)$ & 0.665 & $(1.7)$ \\
$\beta_{\text {Women }}$ & women & {$[0,1]$} & 1 & 0.439 & $(1.5)$ & 0.518 & $(1.8)$ \\
$\beta_{\mathrm{ASA} 2}$ & ASA2 & {$[0,1]$} & 2 & & & -0.353 & $(-0.8)$ \\
$\beta_{\text {Centre }}$ & origin in central zone & {$[0,1]$} & 1 & 0.628 & $(0.8)$ & 0.6524 & $(0.9)$ \\
$\beta_{\mathrm{DL}}$ & dummy for driving licence & {$[0,1]$} & 1 & 0.649 & $(2.7)$ & 0.6232 & $(2.1)$ \\
$\beta_{\mathrm{CO}}$ & dummy for vehicle ownership & {$[0,1]$} & 1 & -0.142 & $(-0.5)$ & & \\
\hline & Initial likelihood & & & -230.125 & & -230.125 & \\
& Final likelihood & & & -201.377 & & -200.779 & \\
& $\rho^{2}$ & & & 0.125 & & 0.128 & \\
\hline
\end{tabular}

Alternatives: 1 Evacuate; 2 Not evacuate

Table 3: Generation model for non-resident category.

\begin{tabular}{lcc}
\hline Parameter & $\mathrm{m}_{\mathrm{e}}{ }^{\mathrm{k}}$ value & $\xi^{\mathrm{k}}$ value \\
\hline Employee coefficient $(\mathrm{k}=\mathrm{W})$ & 0.77 & 0.75 \\
Occasional customer coefficient $(\mathrm{k}=\mathrm{C})$ & 0.80 & 0.67 \\
School staff coefficient $(\mathrm{k}=\mathrm{S})$ & 0.88 & 1.00 \\
Weak user coefficient $(\mathrm{k}=\mathrm{D})$ & 1.00 & 1.00 \\
\hline
\end{tabular}


Table 4: $\quad$ Calibrated parameter of modal choice model.

\begin{tabular}{llccc}
\hline Parameter & Alt. & Value & t-statistic \\
\hline$\beta_{\mathrm{R}^{5}}$ & dummy equal to 1 for citizen users of age in range [25,45] & 1 & 3.071 & $(-1.90)$ \\
$\beta_{\mathrm{DPrc}}$ & distance as the crow flies between origin r and refuge area c & 1 & -0.003 & $(-1.90)$ \\
$\beta_{\mathrm{L}}$ & economic dummy (professional level) & 2 & 1.183 & $(-0.7)$ \\
$\beta_{\mathrm{CWork}} \quad$ dummy equal to 1 if car is used to go to work, 0 otherwise & 2 & 0.304 & $(-0.5)$ \\
$\beta_{\text {Women }} \quad$ dummy for women & 1 & 1.939 & $(-1.3)$ \\
\hline Initial likelihood & & -14.560 & -7.680 \\
Final likelihood & & 0.470 & \\
$\rho^{2}$ & &
\end{tabular}

Table 5: $\quad$ Calibrated parameter of distribution model.

\begin{tabular}{|c|c|c|c|c|}
\hline \multicolumn{2}{|c|}{ Parameters } & Alt. & Value & $\mathrm{t}$-Statistic \\
\hline$\beta_{\text {Women }}$ & dummy women & 2 & 2.829 & 2.700 \\
\hline$\beta_{\mathrm{L} 2}$ & economic dummy & 1 & -0.776 & -0.900 \\
\hline$\beta_{\text {гр }}$ & dummy for origin not in the centre & 1 & 3.898 & 3.100 \\
\hline$\beta_{\text {Dr,ncf }}$ & distance as the crow flies between origin $r$ and refuge area ncf & 2 & -0.002 & -2.200 \\
\hline \multicolumn{2}{|c|}{ Initial likelihood } & & -39.509 & \\
\hline \multicolumn{2}{|c|}{ Final likelihood } & & -21.668 & \\
\hline \multicolumn{2}{|l|}{$\rho^{2}$} & & 0.452 & \\
\hline
\end{tabular}

Alternatives: cf fixed refuge area; ncf non-fixed refuge area

Table 6: $\quad$ Calibrated parameter of distribution with modal choice model.

\begin{tabular}{llccc}
\hline Parameters & Alt. & Value & t-Statistic \\
\hline$\beta_{\mathrm{TPr}, \mathrm{cf}} \quad$ time on pedestrian network from origin $\mathrm{r}$ to fixed refuge area c & 1 & -0.269 & $(-1.4)$ \\
$\beta_{\mathrm{TPr}, \mathrm{ncf}} \quad$ time on pedestrian network from origin $\mathrm{r}$ to non-fixed refuge area c & 2 & -1.026 & $(-1.5)$ \\
$\beta_{\mathrm{TS}, \mathrm{cf}} \quad$ time on road network from origin r to fixed refuge area c & 3 & -1.967 & $(-1.3)$ \\
\hline Initial likelihood & \multicolumn{3}{c}{-40.649} \\
Final likelihood & -33.563 \\
$\rho^{2}$ & \multicolumn{3}{c}{0.17} \\
\hline Alternatives:1 pedes. with fixed refuge area; 2 pedes. with non-fixed refuge area; 3 car with fixed refuge area.
\end{tabular}

\section{Conclusion}

In this paper an advancement was made in models simulating transport demand in emergency conditions. A generation model according to a descriptive and a behavioural approach is proposed, representing an advance over models found in the literature. A first example of modal choice with a distribution model is presented, since in emergency conditions standard procedures have to be rearranged. In comparison with a previously presented paper, much attention was devoted to SP surveys: all models are calibrated using SP data and RP data, which are considered similar to SP with physical verification. Our future objective is to improve databases, in order to obtain better results from formal tests related to parameters and apply the proposed models to different scenarios. Moreover, a sequential model [11] could be proposed, in order to verify whether or not evacuation probability varies if users have previously participated in evacuation trials, according to their previous choices and previous experience. 


\section{Acknowledgement}

Partially supported by Regione Calabria (EU Structural Fund 2000-2006) in the framework of the SICURO project (note no. 19193 of November 23, 2004, on the implementation of measure 3.16 action 3.1.a.3).

\section{References}

[1] Ben Akiva M., Lerman S., Discrete choice analysis: theory and application to travel demand, MIT Press, Cambridge, MA, 1985.

[2] Biggiero L., Russo F., Il progetto di un'indagine rp-sp per la calibrazione congiunta di modelli di domanda intercity passeggeri e merci. In Il trasporto pubblico nei sistemi urbani e metropolitani, Amoroso S. and Crotti A. (Eds.), FrancoAngeli, Milan, 1997.

[3] Cascetta E., Russo F., Calibrating aggregate travel demand models with traffic counts: Estimators and statistical performance. In Transportation, Vol. 24, 271-293, 1997.

[4] Cascetta E., Transportation systems engineering: theory and methods, Kluwer Academic Press, 2001.

[5] Domencich T.A., McFadden D. Urban travel demand: a behavioural analysis, American Elsevier, New York, 1975.

[6] Lavanco G., Psicologia dei disastri. Comunità e globalizzazione della paura. Franco Angeli, Milan, 2003.

[7] Russo F., Vitetta A., Risk in anthropic environments: methodologies for risk evaluation and exposition reduction. In Environmental Health Risk III, Brebbia et al. (ed.), WIT Press, Boston, 2005.

[8] Russo F., Vitetta A., Security and Safety in transportation system: models for evacuation analysis in emergency conditions. In International Journal of Sustainable Development and Planning, Vol.1, Issue 2, 2006.

[9] Russo F., Vitetta A., An assignment model with modified Logit, which obviates enumeration and overlapping problems, Transp., 33,347-370,2006.

[10] Russo F., Vitetta A., Safety of users in road evacuation: general methodology and main results. In Urban Transport XIII, Brebbia C.A. (ed.), WIT Press, 763-772, 2007, and in Urban Transport: Safety of Users in Road Evacuation, Russo F. (ed.), WIT Press, 1-10, 2007.

[11] Russo F., Chilà G., Sequential models for the mobility decisions: experimentation for the vehicle holding choices. In Proceedings of European Transport Conference 2007, The Netherlands, 2007.

[12] Russo F., Chilà G. (2007) Safety of users in road evacuation: demand models. In Urban Transport XIII, Brebbia C.A. (ed.), WIT Press, 773-782, 2007, and in Urban Transport: Safety of Users in Road Evacuation, Russo F. (ed.), WIT Press, 11-20, 2007.

[13] Russo F., Chilà G., Domanda di trasporto in condizioni di emergenza. Modelli e metodi per la simulazione, applicazione ad un caso reale, Franco Angeli, Milan, 2007. 
[14] Wilmot C.G., Fu H., A sequential logit dynamic travel demand model for hurricane evacuation. In Transp. Research Record, Vol.1882, 19-26, 2004.

[15] Wilmot C.G., Fu H., Static vs. Dynamic and Aggregate vs. Disaggregate: A Comparison Between Practice and Research in Hurricane Evacuation Travel Demand Modeling. In Transp. Research Board 86th Annual Meeting, 2007.

[16] Wilmot C.G., Fu H., Zhang H., Modeling the Hurricane Evacuation Response Curve. In Transp. Research Record, Issue 2022, 94-102, 2007. 